\title{
Processo de congelamento em túnel portátil com convecção forçada por exaustão e insuflação para paletes
}

\author{
Freezing process evaluation using a portable forced air system with air evacuation and air blowing in pallets
}

\author{
Douglas Fernandes BARBIN ${ }^{1 *}$, Lincoln Camargo NEVES FILHO ${ }^{1}$, Vivaldo SILVEIRA JUNIOR ${ }^{1}$
}

\begin{abstract}
Resumo
Este trabalho propôs a montagem experimental de um túnel portátil de congelamento por ar forçado composto por um ventilador que produz uma região de alta ou baixa pressão em um palete com produto, onde se pode avaliar o processo com a utilização de insuflação, exaustão de ar e uma combinação mista destes dois processos. O equipamento foi alocado no interior de uma câmara de estocagem de produtos congelados, buscando-se melhorar a distribuição do ar, potencializando-se a troca térmica entre o ar e o produto. Durante o congelamento, foram comparados os processos e analisada a transferência de calor entre o ar de resfriamento e o produto em diferentes posições e camadas do palete, bem como a distribuição do ar de resfriamento em circulação ao redor do produto. O processo de exaustão apresentou uma redução de $14 \%$ do tempo para o congelamento em relação à insuflação e $10 \%$ em relação ao misto.

Palavras-chave: congelamento de alimentos; câmara de estocagem; túnel de congelamento.
\end{abstract}

\begin{abstract}
The objective of this work is to build an experimental portable forced-air freezing tunnel which creates a low or high pressure region surrounding the product. Comparative studies with air exhausting and blowing were conducted. The tunnel was built and placed inside a freezing product storage chamber, and the objective was to improve the air circulation and the thermal distribution between the product and cold air for a sample batch left inside the chamber. A heat transfer analysis comparing the process and the air distribution around the product was performed. The air evacuation process reduced up to $14 \%$ of the freezing time in relation to the blowing system and $10 \%$ in relation to the mixed system.
\end{abstract}

Keywords: frozen foods; freezing tunnel; storage room.

\section{Introdução}

Os processos de resfriamento e congelamento dos alimentos reduzem efetivamente reações químicas e biológicas desencadeadas pela atividade de microrganismos e enzimas, além do fato da cristalização da água livre nos alimentos reduzir a atividade de água, retardando assim o processo de deterioração do alimento (ASHRAE, 2002; DELGADO; SUN, 2001; HELDMAN, 1992; SALVADORI; MASCHERONI, 1996; WELTI-CHANES et al., 2005).

No sistema de resfriamento por ar forçado, é utilizado ar a baixa temperatura como meio de resfriamento, baseado no princípio de convecção. $\mathrm{O}$ ar é forçado através do produto, geralmente embalado em caixas, de forma a reduzir o tempo de congelamento (THOMPSON, 2004). Este processo pode ser aplicado em equipamentos de funcionamento contínuo ou em batelada. Entre os processos realizados em batelada estão os de congelamento de polpas de frutas embaladas em sacos plásticos de polietileno.

O produto deve permanecer no túnel o tempo necessário para que a temperatura no seu centro térmico seja reduzida até o patamar desejado, sendo então transferido para uma câmara de estocagem para manutenção desta condição até o momento da comercialização (FRASER, 1998; SANTOS, 2005). Porém, isto requer um alto investimento inicial, já que é necessária a utilização de dois ambientes ou equipamentos diferentes.

Os sistemas de refrigeração para estocagem de produtos congelados são normalmente dimensionados para operação com uma carga máxima, ou seja, operando nas condições mais críticas do ambiente e que é superior à carga variável utilizada durante a maioria do tempo de operação (TALBOT; FLETCHER, 1996). Assim é possível utilizar a capacidade variável do sistema de refrigeração para seu aproveitamento nesta aplicação.

Os equipamentos por ar forçado podem solucionar muitas dificuldades no processo de resfriamento, por promover a circulação do ar entre os produtos embalados (TALBOT; CHAU, 1998).

As câmaras frigoríficas podem ser usadas ou adaptadas para realizar o resfriamento por ar forçado com um custo reduzido,

Recebido para publicação em 20/2/2008

Aceito para publicação em 25/9/2008 (003240)

${ }^{1}$ Departamento de Engenharia de Alimentos, Faculdade de Engenharia de Alimentos, Universidade Estadual de Campinas - Unicamp, Rua Monteiro Lobato, 80, CP 6121,

CEP 13083-862, Campinas - SP, Brasil, E-mail:dfbarbin@yahoo.com.br

${ }^{*}$ A quem a correspondência deve ser enviada 
aproveitando-se o superdimensionamento e ociosidade dos sistemas de refrigeração quando projetados.

Até o momento não se tem conhecimento de pesquisas na literatura disponível que avaliem a eficiência de um túnel portátil utilizado em processos de congelamento.

O tempo de resfriamento em sistemas de refrigeração por ar forçado é determinado pela temperatura do meio, pelo fluxo de ar e pela disposição e geometria do produto. O sistema por ar forçado pode ser com exaustão ou insuflação de ar. Para o congelamento industrial de alimentos, é comum a utilização de túneis de insuflação direta de ar.

Resende e Silveira Jr. (2002b) mostraram que os perfis de velocidade em túneis de congelamento por ar forçado são fortemente influenciados por quaisquer alterações na quantidade de produto e na sua distribuição no interior do equipamento, fazendo com que o escoamento ocorra através de caminhos preferenciais, podendo levar a erros comuns na determinação de tempos de congelamento e coeficientes de transferência de calor nestes equipamentos. Foi mostrado, ainda, que a transferência de calor pode ser constante através da superfície do produto, porém podem existir variações nos coeficientes de transferência de calor de acordo com as diferentes posições do produto e com sua distribuição dentro do compartimento de congelamento.

Dentre os fatores que influenciam a taxa de resfriamento por ar forçado, além da diferença de temperatura, estão a área de superfície de contato do meio de resfriamento com o produto, velocidade do ar de resfriamento e orientação da montagem e empilhamento do produto a ser resfriado (BAIRD et al., 1988; FRASER, 1998; LAGUERRE et al., 2006).

Promover a exaustão do ar, ao invés da insuflação, é mais adequado de forma a evitar que o ar passe por caminhos preferenciais, promovendo uma troca de calor mais uniforme (FRASER, 1998). O resfriamento convencional por ar forçado é uma alternativa eficiente na retirada do calor de campo de frutas e hortaliças, melhorando seu processo de conservação pós-colheita (ANTONIALI; CORTEZ, 2000) em processos de resfriamento de frutas. Neste sentido, o túnel de resfriamento por ar forçado à exaustão é muito utilizado. Esta forma de operação altera um dos pontos críticos do processo, que é o controle do fluxo do ar, já que ele determina a eficiência e homogeneidade dos tratamentos aos quais os produtos são submetidos.

Assim, os objetivos deste trabalho foram a determinação do perfil de velocidade do ar no escoamento e cálculo da vazão; caracterização da distribuição do ar no interior da montagem através da monitoração das temperaturas do ar e do produto em diferentes posições e comparação das variações, levando em consideração a localização entre as camadas de caixas no palete; avaliar a viabilidade de um equipamento portátil do tipo túnel de exaustão como alternativa para o congelamento de produtos em câmaras de armazenamento, de maneira que não se faça necessário um investimento complementar em equipamentos como um túnel de congelamento.

\section{Material e métodos}

\subsection{Preparação das amostras}

Para simulação da polpa de fruta, foi utilizada uma solução modelo de 15\% (massa/massa da solução) de sacarose, de forma a simular a composição de sólidos solúveis e $0,5 \%$ (massa/massa da solução) de goma espessante carboximetilcelulose (Carbocel AM, Arinos, SP, Brasil), para conferir viscosidade à solução, simulando a consistência de polpas de frutas.

Para o preparo da solução, a carboximetilcelulose em pó foi misturada à sacarose e em seguida adicionada lentamente em tanque com água fria sob agitação (agitador de três hélices, com motor de 0,5 cv e $1150 \mathrm{rpm}$ ) (Weg Equipamentos Elétricos S.A., SP, Brasil - modelo 07/00 FM45885) até a completa dispersão. Foram adicionados à solução, sob agitação, 1000 ppm de benzoato de sódio.

A solução modelo foi envasada em embalagens de polietileno de $9,5 \times 7 \times 1,5 \mathrm{~cm}$, com $100 \mathrm{~g}$ de produto em cada uma e acondicionadas nas caixas de plástico para o processo de congelamento.

\subsection{Montagem do túnel portátil}

O sistema de congelamento projetado é constituído por um equipamento de ar forçado piloto, onde foi analisado o comportamento das temperaturas das amostras durante o processo de congelamento por convecção de ar forçado, para exaustão, insuflação e misto (parte do tempo de insuflação e parte de exaustão, e vice-versa). O sistema foi montado com uma cobertura plástica conectada a um ventilador, através de um duto, que promove a movimentação do ar através do produto. Esta cobertura plástica envolve as caixas contendo o produto, empilhadas sobre um palete de transporte comercial.

$\mathrm{O}$ ar interno de uma câmara de estocagem é forçado sobre o palete, promovendo o resfriamento do produto ao passar pelas áreas de abertura da caixa e através do produto.

Na exaustão, o sistema é montado de forma que o duto seja conectado à sucção do ventilador, direcionando o fluxo de ar do produto através do ventilador para o evaporador no interior da câmara. Na insuflação, a conexão é invertida e conectada à saída do ventilador, que insufla o ar frio do interior da câmara diretamente para as amostras.

A circulação do ar forçado no interior da montagem tem direção vertical, tanto na insuflação como na exaustão, diferentemente de outros túneis encontrados comercialmente e na literatura (RESENDE; SILVEIRA Jr., 2002a). Na exaustão, o sentido é da base do palete para a parte superior, enquanto na insuflação o ar é forçado da parte superior do palete até a base, conforme ilustrado na Figura 1.

Também foram realizados experimentos denominados mistos, nos quais foram utilizados os dois sentidos de circulação do ar (insuflação e exaustão) num mesmo ensaio. Cada um deles foi realizado durante aproximadamente metade do tempo de processo. 


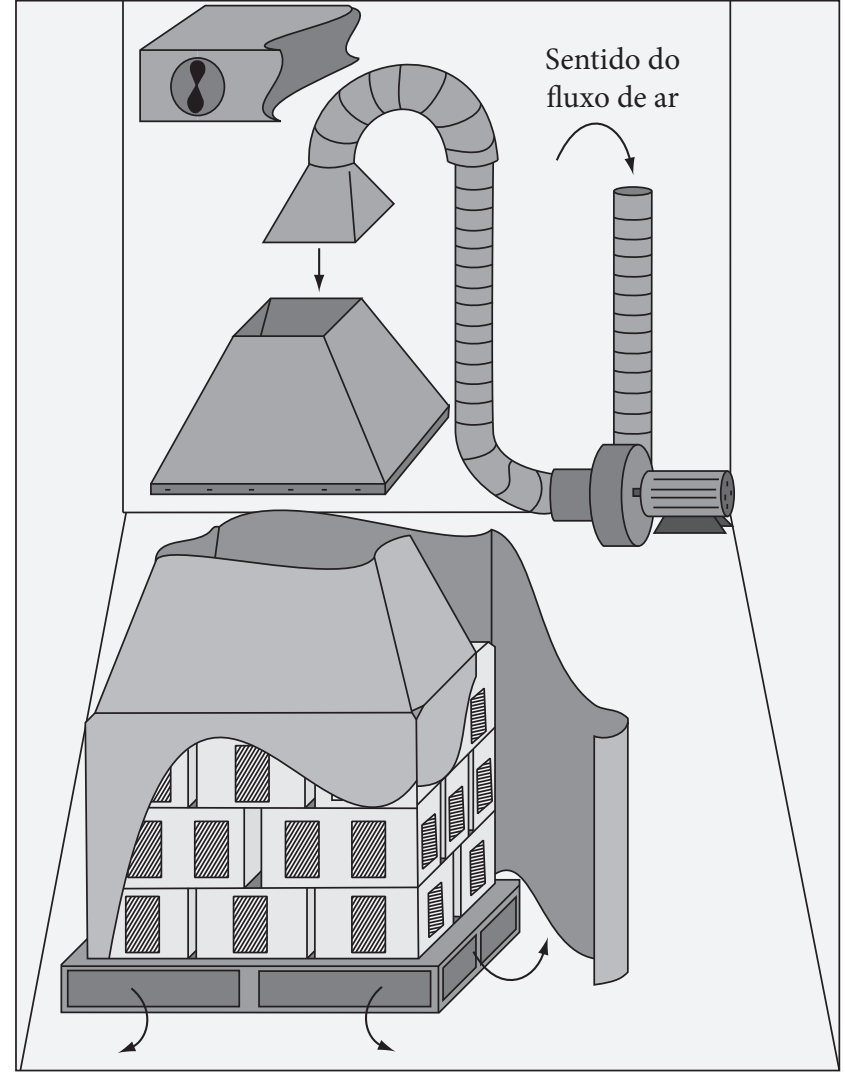

Insuflação

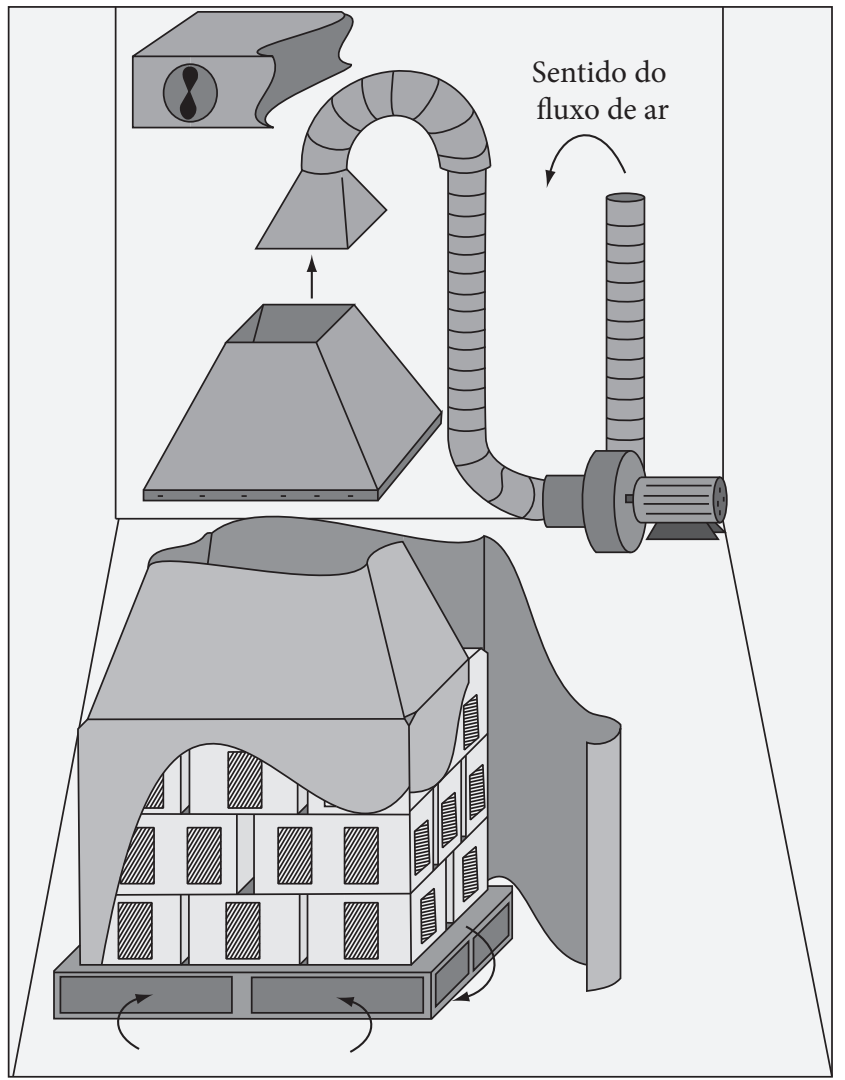

Exaustão

Figura 1. Montagem do túnel portátil com o empilhamento das caixas cobertas com o plástico e posicionamento do ventilador durante a insuflação e exaustão.

Dois ensaios deste tipo foram testados, um iniciado com a exaustão do ar e, após aproximadamente 24 horas, invertido para insuflação; outro iniciado com insuflação e alterado para exaustão.

O ventilador utilizado no túnel portátil é do tipo de hélices axiais com motor de indução trifásico da Weg, modelo 71586 e $0,5 \mathrm{cv}$, acoplado ao duto de alumínio flexível, que por sua vez foi conectado à estrutura metálica do difusor que realizará a sustentação da cobertura plástica sobre o palete.

Todo o conjunto de equipamentos foi alocado no interior de uma câmara de estocagem de produtos congelados, marca Recrusul, com dimensões internas de $3 \times 3 \times 2,3 \mathrm{~m}\left(20,7 \mathrm{~m}^{3}\right)$.

O túnel portátil foi montado para o desenvolvimento dos testes com dimensões reais dos paletes utilizados em processos industriais de congelamento. A câmara utilizada estava dimensionada para estocagem de produtos já congelados, e não para o processo de congelamento propriamente dito.

\subsection{Distribuição dos sensores nos produtos}

O sistema de monitoração utilizado consiste de uma chave automática seletora de canais modelo Scanner 706 da Keithley Instruments Inc, OH, USA, com capacidade de varredura de 100 canais. A abertura e o fechamento dos canais são comandados através de um controlador GPIB da STD (modelo STD8410), conectado em um microcomputador.

A numeração dos termopares, bem como sua posição na montagem, é apresentada na Figura 2.

As temperaturas das amostras foram monitoradas através de termopares de cobre-constantan (tipo T).

As soluções modelo preparadas foram acondicionadas no interior da câmara de congelamento e sob o equipamento de circulação de ar para estudo do processo de congelamento. Foram utilizadas 35 caixas plásticas. As caixas foram empilhadas sobre um palete padronizado de $1,00 \times 1,20 \mathrm{~m}$, em sete camadas, com cinco caixas em cada camada, encostadas lateralmente umas às outras, conforme a montagem utilizada industrialmente, a fim de impedir a formação de caminhos preferenciais para a circulação de ar sem que este entre em contato com o produto.

$\mathrm{Na}$ distribuição das embalagens de produtos nas caixas, foram colocadas oitenta e quatro embalagens por caixa, distribuídas em cinco camadas (superior, centrais e inferior), sendo três camadas com vinte unidades, e duas camadas com doze unidades, intercaladas e com espaços para a passagem do ar, totalizando $8,6 \mathrm{~kg}$ de produto por caixa. A Figura 3 mostra esta distribuição. 

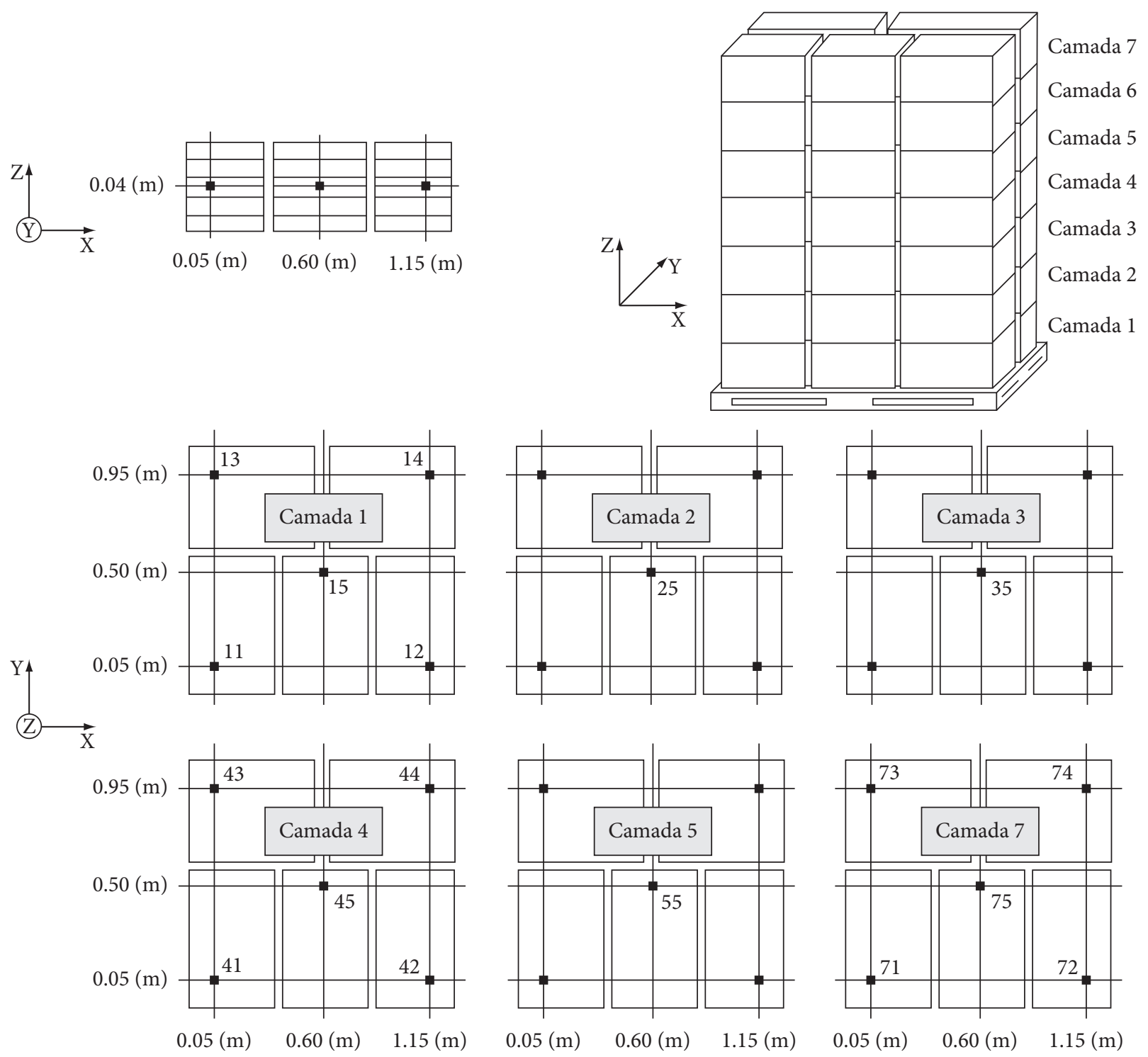

Figura 2. Distribuição e identificação da localização dos sensores de temperatura utilizados na montagem do palete com sete camadas de caixas.

(a)

(1)

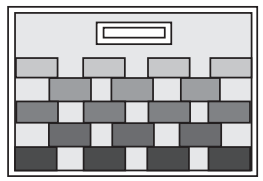

Figura 3. Distribuição das embalagens de polietileno nas caixas: a) vista superior; e b) vista de perfil.

Foi monitorada uma amostra em cada vértice das camadas 1, 4 e 7, além de uma amostra na posição geometricamente central da camada. Nas outras camadas, foi monitorada apenas uma amostra na posição geometricamente central da camada, totalizando assim 18 pontos de monitoração de temperaturas nas amostras. As localizações dos sensores são apresentadas na Figura 2. Nota-se que a $6^{a}$ camada não foi instrumentada, já que o objetivo era monitorar as camadas das extremidades superior e inferior (camadas 1 e 7), e camada central (camada 4), realizando apenas o acompanhamento nas demais camadas intermediárias, priorizando aquelas mais próximas ao centro geométrico da montagem.

Os sensores foram posicionados no centro de cada amostra monitorada.

Também foram distribuídos outros quatro sensores para monitoração das temperaturas do ar de circulação no interior da câmara e no palete, sendo um no ar de insuflação do evaporador da câmara, um no retorno do ar, próximo ao sensor de temperatura do termostato da câmara, um na parte superior e um na parte inferior da montagem de caixas do palete.

Para minimizar os efeitos da diferença de temperatura inicial do produto e o problema de estabilização e manutenção 
da temperatura do ar no interior da câmara, deixou-se o palete dentro da câmara, isolado termicamente, para que o sistema de refrigeração fosse ligado e não houvesse alteração significativa na temperatura do produto.

Assim, foram utilizadas placas de poliestireno expandido montadas ao redor do palete, dispostas de maneira a formar uma barreira térmica e um tapete de borracha na base da câmara, sob o palete, para manter a temperatura do produto sem influência da temperatura do ar interno, no início dos ensaios até que a câmara estivesse com sua condição de temperatura estável para o início dos ensaios.

Esta metodologia foi adotada para que os ensaios tivessem início com as amostras a uma temperatura comum e homogênea, de forma a simular a entrada do produto na câmara num processo real. Este procedimento foi devido à impossibilidade de retirada e realocação do sistema na câmara a cada novo ensaio.

\subsection{Determinação do tempo de congelamento}

Nesta etapa, foi determinado o tempo de congelamento total, sendo o tempo necessário para reduzir a temperatura do produto desde a temperatura de equilíbrio do palete de $15^{\circ} \mathrm{C}$, passando pelo ponto de início de congelamento, até que o centro térmico atingisse $-18^{\circ} \mathrm{C}$. Esta temperatura foi escolhida por ser a mais comumente utilizada comercialmente e por representar um parâmetro em que já se encontram poucas atividades enzimáticas e microbiológicas no alimento.

Os tempos foram monitorados desde o momento em que o sistema de refrigeração foi acionado $($ tempo $=0)$. Porém, para avaliação da eficiência do equipamento ou comparação com o teste de referência, o tempo de congelamento foi considerado a partir do momento da retirada dos painéis de poliestireno laterais do palete, por volta de 5 horas após o acionamento da câmara, destacando-se pelo sobressalto da temperatura do ar conforme as Figuras 6 a 10.

Foram monitoradas as temperaturas do lote de produtos durante o congelamento e da temperatura interna da câmara para determinar as condições de operação sobre o produto que estava armazenado à temperatura de equilíbrio. Desta maneira também foi possível acompanhar as alterações de temperatura do sistema de controle da câmara.

Nesta etapa foi possível analisar o perfil de temperatura durante o processo de congelamento das amostras monitoradas, verificando a diferença existente entre as temperaturas das amostras, relativas à sua localização na montagem em circulação do ar por insuflação, misto, exaustão e sem o túnel portátil.

Os ensaios de insuflação e exaustão foram realizados em triplicatas. Para os ensaios mistos, foi realizado um experimento para cada configuração (insuflação-exaustão, e exaustãoinsuflação).

A partir dos resultados obtidos para a variação da temperatura do produto ao longo do processo de congelamento, em função de sua posição na camada monitorada $(T(x, y, z, t))$, uma regressão foi feita, utilizando recursos do software
TableCurve $2 \mathrm{D}^{\circledR}$, para o melhor ajuste ao modelo, a partir dos resultados obtidos experimentalmente. Estes ajustes foram feitos para os ensaios de triplicata de exaustão e de insuflação, para comparação entre os processos. Assim, foram construídas as figuras representando a variação da temperatura nas camadas monitoradas com a utilização do software SigmaPlot ${ }^{\oplus}$. As figuras mostram a cinética de resfriamento dos produtos nas camadas durante os processos de congelamento.

Os ensaios mistos foram realizados para comparação com os ensaios realizados com circulação plena. O propósito foi inverter o fluxo de ar no meio do processo para verificar a eficiência dos métodos combinados.

\subsection{Determinação da velocidade do ar de escoamento}

Para as medidas de velocidade do ar, foi utilizado um anemômetro de fio quente (Tri-Sense ${ }^{\varpi}$, modelo EW-37000-00 da Fabricante Cole-Parmer Instrument Company, IL, USA). O fabricante fornece uma incerteza nas leituras de $2 \%$.

O sensor do anemômetro foi inserido através de aberturas no difusor de ar para medição da velocidade do ar em diferentes pontos da área perpendicular ao escoamento. As aberturas foram alinhadas e espaçadas em intervalos regulares. $\mathrm{O}$ sensor foi introduzido variando-se a profundidade da inserção, fornecendo pontos fixos no plano perpendicular ao fluxo de ar, de forma a realizar uma varredura das velocidades do ar medidas através desta área.

Foram medidas as velocidades para comparação entre os ensaios de exaustão e insuflação de ar com o ventilador, operando em regime constante, sem obstruções na linha de escoamento do ar.

Também foi medida a velocidade de circulação do ar no interior da câmara, já que pode ser considerado como o ar de circulação no ensaio de referência, para comparação dos valores de velocidade do ar obtidos com o túnel portátil.

Para o teste de referência (sem o túnel portátil), como não havia o direcionamento do fluxo de ar verticalmente sobre o produto, foram realizadas medidas em diversos pontos, lateralmente ao palete, para comparação com os resultados de velocidade do ar com a utilização do túnel portátil. Entretanto, o fluxo de ar pode ser considerado cruzado ao palete, diferentemente dos fluxos ascendente ou descendente dos processos de exaustão e insuflação, respectivamente.

\section{Resultados e discussão}

\subsection{Avaliação da distribuição da velocidade do ar}

Os gráficos mostrados na Figura 4 e Figura 5 ilustram os resultados experimentais das medidas de velocidade do ar no escoamento para os ensaios de insuflação e exaustão, em função da posição no plano compreendido pela área da superfície do palete, tendo como coordenadas as medidas de comprimento $(\mathrm{y}(\mathrm{cm}))$ e da largura $(\mathrm{x}(\mathrm{cm}))$. As leituras das velocidades estão apresentadas no eixo vertical $\mathrm{z}\left(\mathrm{m} . \mathrm{s}^{-1}\right)$. Para facilitar a 


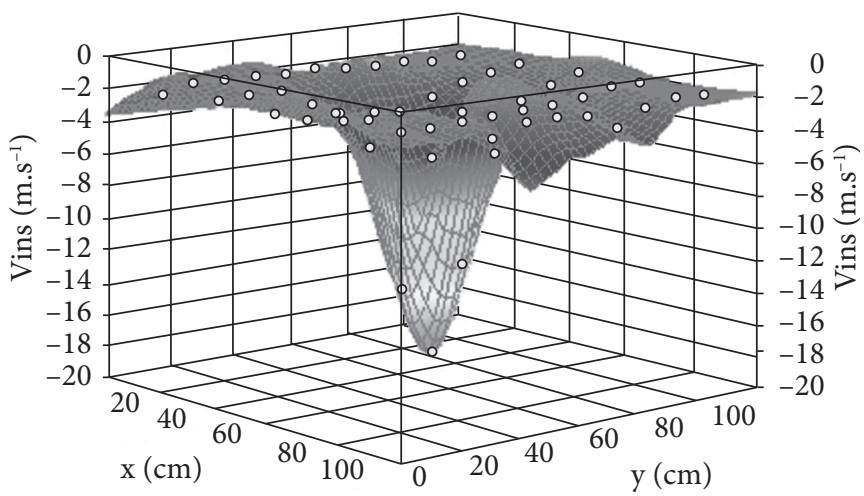

Figura 4. Distribuição da velocidade do ar normal à seção de escoamento na superfície do palete para o processo de insuflação.

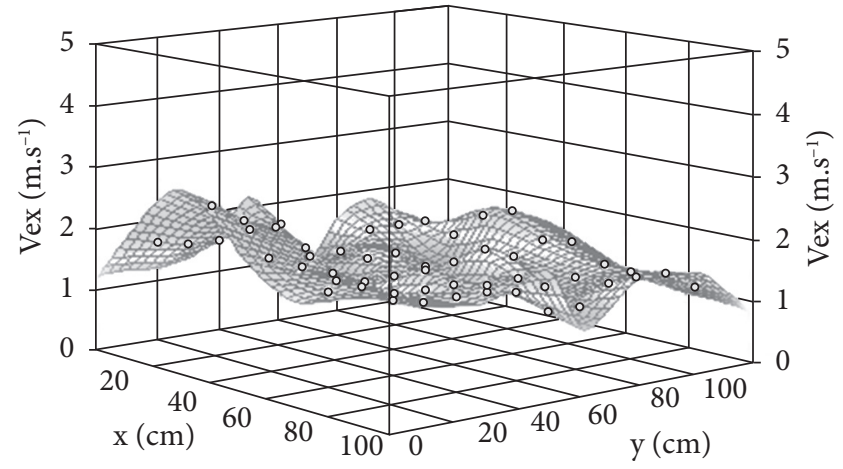

Figura 5. Distribuição da velocidade do ar normal à seção de escoamento na superfície do palete para o processo de exaustão.

visualização da distribuição dos pontos experimentais das leituras, foi traçada uma superfície, unindo estes resultados.

No processo de insuflação, observou-se a presença de valores altos para a velocidade, acima de $15 \mathrm{~m} . \mathrm{s}^{-1}$, registradas na parte central da região de tomadas de medidas, enquanto nas regiões periféricas do plano as velocidades são mais moderadas, variando entre 1 e $2 \mathrm{~m} . \mathrm{s}^{-1}$. Esta falta de uniformidade na distribuição das velocidades, não é observada na exaustão.

Este fato ocorre devido à sucção do ar ser realizada de forma mais homogênea, promovendo a distribuição e circulação do ar de maneira mais uniforme dentro do túnel, além de existir uma maior perda de carga quando a exaustão é realizada no palete de produtos, e não no ar interior da câmara. Isto mostra que o ar não teve uma distância suficiente para percorrer entre a parte superior da coifa, na conexão com o duto de escoamento, e a parte inferior, em contato com a camada mais alta das caixas, impossibilitando que ocorresse a distribuição de maneira uniforme.

$\mathrm{Na}$ insuflação o ar está a uma velocidade maior na região central da área monitorada e não tem espaço suficiente para distribuir igualmente o fluxo ao entrar em contato com o produto. Isto pode ter causado uma mudança do sentido de deslocamento do ar nas extremidades da área do plano de tomada de medidas.
O sinal negativo para o valor da velocidade na insuflação representa o sentido do fluxo, inverso ao da exaustão, conforme o eixo z do gráfico apresentado na Figura 4.

Para um estudo de resfriamento de esferas plásticas preenchidas com uma solução de carragena, Allais et al. (2006) mostraram que o aumento da velocidade do ar de escoamento reduziu o tempo de meio resfriamento das amostras. Porém esta variação é exponencial e a redução tende a ser menor a partir de valores de velocidade de $2 \mathrm{~m} \cdot \mathrm{s}^{-1}$.

Dussán Sarria et al. (2006) mostraram que altas velocidades do ar de escoamento causaram reduções na eficiência do processo de resfriamento, menores valores de taxa de resfriamento experimentais e maiores valores de tempo de processo. O aumento da velocidade do ar de 1,3 para 2,0 $\mathrm{m} \cdot \mathrm{s}^{-1}$ não apresentou diferença significativa para os resultados do tempo de resfriamento. Segundo o autor, isto ocorre provavelmente devido à criação de fluxos preferenciais que não permitem o resfriamento adequado dos produtos.

Os valores encontrados para a velocidade do ar nos ensaios de referência foram de $1,5 \mathrm{~m} \cdot \mathrm{s}^{-1}$.

\subsection{Análise dos ensaios de referência, exaustão, misto e insuflação de ar no palete}

\section{Ensaio de referência (sem o túnel portátil)}

No ensaio de referência, houve pontos que não atingiram a temperatura de $-18{ }^{\circ} \mathrm{C}$ na camada central, mostrando a desigualdade do processo quando não foi utilizado o túnel. A maioria dos pontos desta camada atingiu $-18^{\circ} \mathrm{C}$ após 37 horas, com exceção de uma das extremidades, que não chegou a congelar durante o processo. As camadas superior e inferior, porém, tinham todos os pontos monitorados congelados após 35 horas de processo.

\section{Ensaios de insuflação, exaustão e misto}

Os ensaios de exaustão mostraram que a diferença de temperatura entre as camadas durante o processo de congelamento foi menor, comparada à diferença entre as temperaturas das camadas no processo de insuflação.

As Figuras 6 a 10 mostram que os processos mistos tiveram uma tendência de resultados próximos aos processos plenos. O ensaio que foi iniciado com a exaustão e depois alterado para insuflação, não teve grande diferença do que foi realizado totalmente com exaustão, tendo como tempo final de congelamento 35 horas; resultado semelhante ao que foi iniciado com a insuflação.

Nota-se, porém, a mesma diferença de uniformidade que existiu nos processos de circulação por insuflação: enquanto algumas amostras estão próximas ou até em temperaturas inferiores a $-18^{\circ} \mathrm{C}$, outras ainda estão em temperaturas na faixa de $-5 \mathrm{a}-12{ }^{\circ} \mathrm{C}$, na fase de perda do calor latente.

A Figura 11 apresenta uma comparação entre os tempos de congelamento para os ensaios de exaustão e insuflação, com valores médios das triplicatas, e misto, com a média dos dois ensaios. 


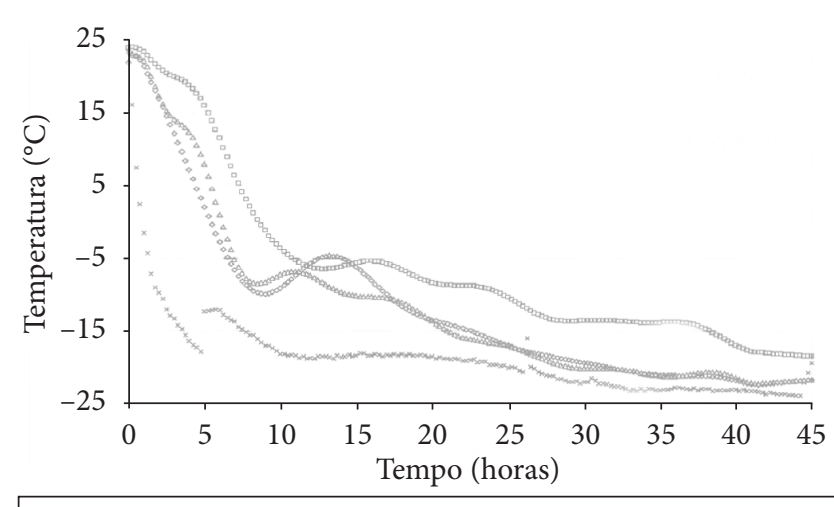

- Camada inferior ^Camada central $\triangle$ Camada superior $\times$ Tar

Figura 6. Cinética de resfriamento do palete: temperatura média das camadas versus tempo de congelamento para o ensaio de referência.

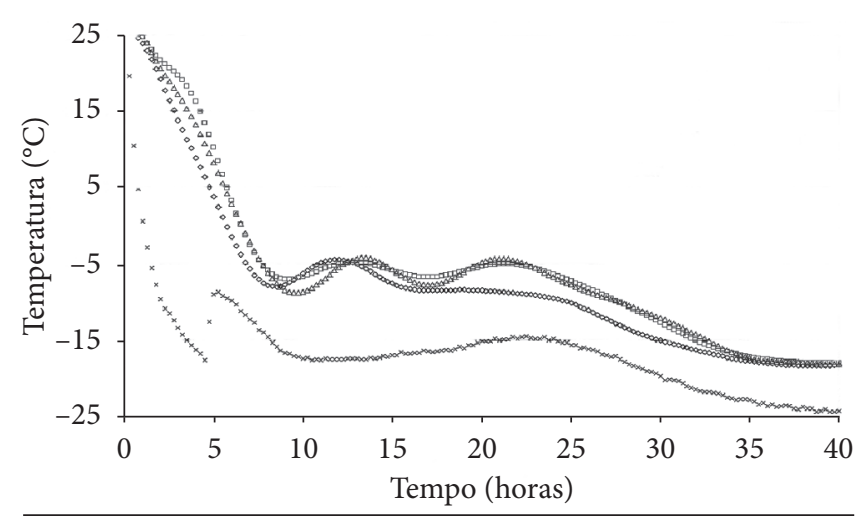

- Camada inferior - Camada central $\triangle$ Camada superior $\times$ Tar

Figura 7. Cinética de resfriamento do palete: temperatura média das camadas versus tempo de congelamento para o ensaio de exaustão.

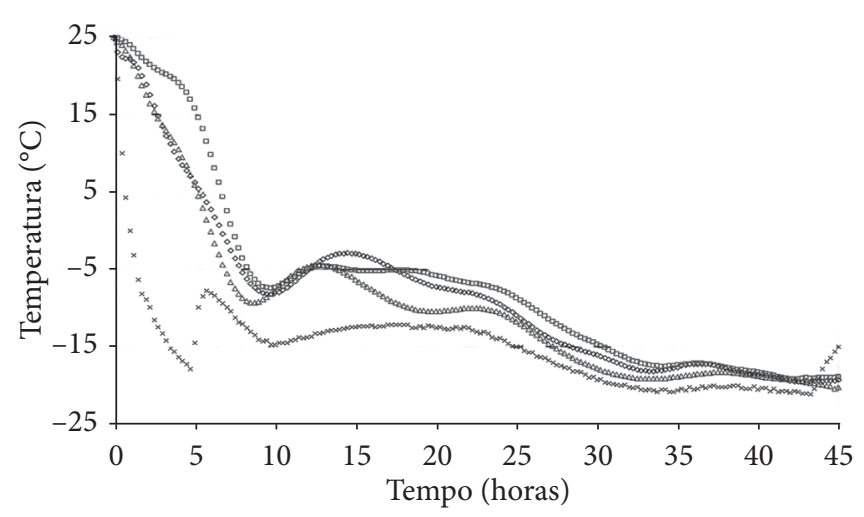

- Camada inferior - Camada central $\triangle$ Camada superior $\times$ Tar

Figura 8. Cinética de resfriamento do palete: temperatura média das camadas versus tempo de congelamento para o ensaio de insuflação.

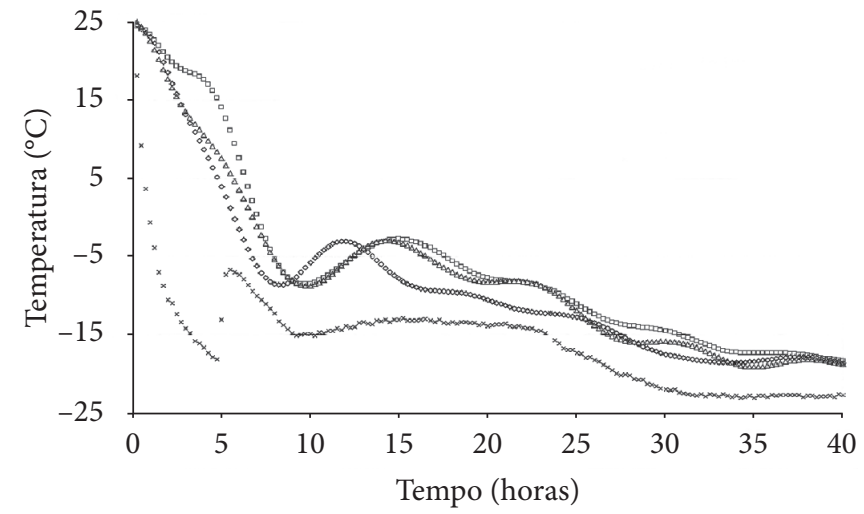

- Camada inferior • Camada central $\triangle$ Camada superior * Tar

Figura 9. Cinética de resfriamento do palete: a) temperatura média das camadas versus tempo de congelamento para o ensaio misto (exaustão-insuflação).

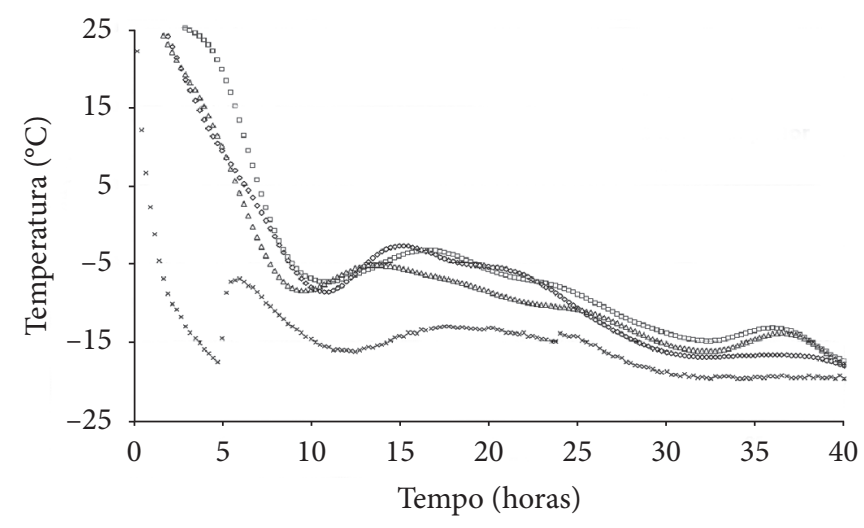

- Camada inferior . Camada central $\triangle$ Camada superior $*$ Tar

Figura 10. Cinética de resfriamento do palete: a) temperatura média das camadas versus tempo de congelamento para o ensaio misto (insuflação-exaustão).

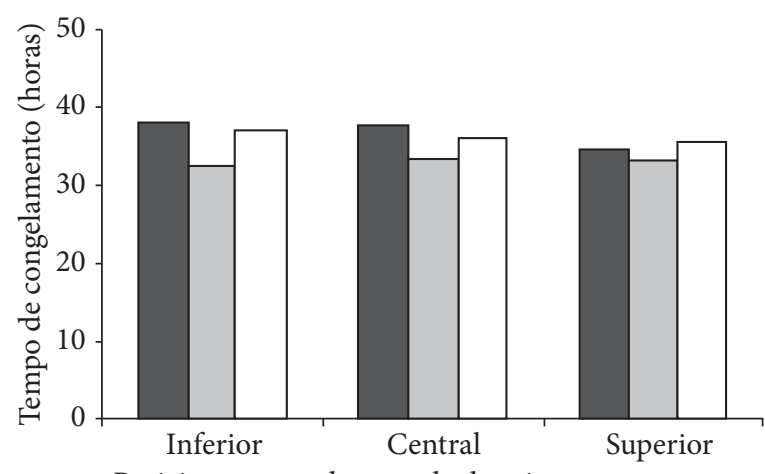

Posicionamento da camada de caixas na montagem

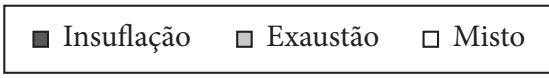

Figura 11. Comparação entre os tempos de congelamento para os ensaios de insuflação, exaustão e misto com a distribuição comercial das embalagens. 
O tempo de congelamento do palete foi entre $34 \mathrm{e}$ 40 horas para a insuflação e de 30 e 33 horas para exaustão. A falta de uniformidade ocorreu também nesta análise, em que, quando a primeira amostra atingiu $-17^{\circ} \mathrm{C}$, o ponto mais quente monitorado ainda estava em $-13{ }^{\circ} \mathrm{C}$. Já na exaustão, a temperatura do ponto mais quente, no momento em que o mais frio atingiu $-17^{\circ} \mathrm{C}$, não foi em nenhum ensaio superior $\mathrm{a}-15{ }^{\circ} \mathrm{C}$.

Resultados obtidos por Vigneault (2004a,b) mostram que fluxos de ar acima de $2 \mathrm{~L} / \mathrm{s}$.kg e velocidades do ar de insuflação maiores que $0,5 \mathrm{~m} \cdot \mathrm{s}^{-1}$ praticamente não influenciaram no tempo de meio-resfriamento de esferas utilizadas no estudo.

Na Figura 7 pode-se observar que, na exaustão, a camada inferior reduziu mais rapidamente a temperatura que as outras. Isto ocorreu de forma semelhante nos outros ensaios, devido à existência de transferência de calor entre o ar da câmara e as amostras das camadas inferiores. $\mathrm{Na}$ insuflação, este resfriamento acelerado ocorre na camada superior, devido ao ar que entra em contato direto com esta camada no processo.

Alvarez e Letang (1994) mostraram que, para um processo de resfriamento por ar forçado a uma velocidade de $1 \mathrm{~m} . \mathrm{s}^{-1}$ no escoamento, existe uma diferença de temperatura entre os produtos colocados na entrada do fluxo de ar (ponto mais 'frio') e os que estão posicionados na outra extremidade da distribuição montada (ponto mais 'quente').

Os resultados dos testes mistos apresentaram resultados intermediários entre os de exaustão e insuflação.

\section{Conclusões}

O processo de exaustão apresentou maior homogeneidade para a velocidade do ar na superfície do palete e uma distribuição mais uniforme também nas camadas inferiores de caixas do palete.

A exaustão oferece um aproveitamento melhor da capacidade da câmara, já que força a passagem do ar de resfriamento igualmente por todas as embalagens em todas as camadas da montagem, passando por todas as amostras igualmente em qualquer ponto do empilhamento, promovendo o resfriamento uniforme, de forma a reduzir o tempo de funcionamento do sistema, além de facilitar a monitoração das condições da montagem, já que se podem considerar todas as amostras na mesma condição de temperatura no regime transiente.

Os resultados obtidos para o ensaio de referência, em que o produto foi congelado sem a utilização do túnel portátil, mostram que a uniformidade e a eficiência do processo são potencializadas com a utilização do equipamento desenvolvido, chegando a uma redução de até 10 horas no tempo de congelamento, representando uma redução de $22 \%$ do tempo de processo.

Analisando-se os dois sentidos de circulação do ar através do conjunto de amostras foi verificado que não existem grandes diferenças no tempo de congelamento da montagem, variando de 1 a 4 horas no tempo de congelamento (10\% do tempo total), com as diferenças causadas pela falta de uniformidade no processo, com alguns pontos em que a circulação do ar não foi eficiente (no caso da insuflação) demorando mais para atingir a temperatura final de congelamento. Isto pode ser causado pelo fato do tempo de congelamento ser um parâmetro majoritariamente dependente da capacidade frigorífica da câmara e, em menor escala, do equipamento de ar forçado.

O uso do túnel portátil mostrou-se útil para redução do tempo de processo, com o direcionamento do ar na exaustão, promovendo distribuição mais homogênea da temperatura na montagem e redução do tempo em $14 \%$.

\section{Referências bibliográficas}

ALLAIS, I.; ALVAREZ, G.; FLICK, D. Modelling cooling kinetics of spheres during mist chilling. Journal of Food Engineering, v. 72, n. 2, p. 197-209, 2006.

ALVAREZ, G.; LETANG, G. Transferts de chaleur et de matiere au sein d'un échanger de type 'palette'. Revue du Froid, v. 47, p. 47-49, 1994.

ANTONIALI, S.; CORTEZ, L. A. B. Resfriamento rápido com ar forçado para conservação pós-colheita de alface "crespa". In: ENCONTRO DE ENERGIA NO MEIO RURAL, 3, 2000, Campinas. Proceedings online... Disponível em: <http://www.proceedings.scielo.br/scielo. php?script=sci_arttext\&pid=MSC0000000022000000100010\&lng= en\&nrm=abn>. Acesso em: 03 Outubro 2005.

ASHRAE. Refrigeration. Atlanta, Georgia: American Society of Heating, Refrigerating and Air Conditioning Engineers, Inc., 2002.

BAIRD, C. D.; GAFFNEY, J. J.; TALBOT, M. T. Design criteria for efficient and cost effective forced air cooling systems for fruits and vegetables. ASHRAE Transactions, Atlanta, v. 94, n. 1, p. 1434-1453, 1988.

DELGADO, A. E.; SUN, D. W. Heat and mass transfer models for predicting freezing processes - a review. Journal of Food Engineering, v. 47, n. 3, p. 157-174, 2001.

DUSSÁN SARRIA, S.; HONÓRIO, S. L.; NOGUEIRA, D. H. Precooling parameters of 'Roxo de Valinhos' figs (Ficus carica L.) packed in a carton box. Fruits, v. 61, n. 6, p. 401-406, Nov. 2006.

FRASER, H. Tunnel Forced-Air Coolers for Fresh Fruits \& Vegetables. Canada: Ministry of Agriculture, Food and Rural Affairs, Government of Ontario, 1998. Disponível em: <http://www. omafra.gov.on.ca/english/engineer/facts/98-031.htm>. Acesso em: Abril 2007.

HELDMAN, D. R. Food Freezing. In: HELDMAN, D. R.; LUND, D. B. Handbook of Food Engineering. New York: Dekker, 1992. p. $277-315$.

LAGUERRE, O.; BEN AMARA, S.; FLICK, D. Heat transfer between wall and packed bed crossed by low velocity airflow. Applied Thermal Engineering, v. 26, n. 16, p. 1951-1960, 2006.

RESENDE, J. V.; SILVEIRA Jr, V. Medidas da Condutividade Térmica Efetiva em Modelos de Polpas de Frutas no Estado Congelado. Ciência e Tecnologia de Alimentos, v. 22, n. 2, p. 177-183, 2002a.

RESENDE, J. V.; SILVEIRA Jr., V. Escoamento de ar através de embalagens de polpa de frutas em caixas comerciais: Efeitos sobre os perfis de velocidade em túneis de congelamento. Ciência e Tecnologia de Alimentos, v. 22, n. 2, p. 184-191, 2002 b. 
SALVADORI, V. O.; MASCHERONI, R. H. Freezing of strawberry pulp in large containers: experimental determination and prediction of freezing times. International Journal of Refrigeration, v. 19, n. 2, p. 87-94, 1996.

SANTOS, C. A. Estudo da Transferência de Calor Durante o Congelamento de Cortes de Aves em Caixas de Papelão Ondulado. Florianópolis, SC, 2005. 99 p. Dissertação (Mestrado) - Universidade Federal de Santa Catarina.

TALBOT, M. T.; CHAU, K. V. Precooling Strawberries. Florida: Agricultural and Biological Engineering Department, Florida Cooperative Extension Service, Institute of Food and Agricultural Sciences, University of Florida, 1998. Disponível em: <http://edis. at.ufl.edu/AE136>. Acesso em: 04 Outubro 2005.

TALBOT, M. T.; FLETCHER, J. H. A Portable Demonstration ForcedAir Cooler. Florida: Agricultural and Biological Engineering Department, Florida Cooperative Extension Service, Institute of Food and Agricultural Sciences, University of Florida, 1996.
Disponível em:<http://edis.at.ufl.edu/AE096>. Acesso em: 12 Setembro 2005.

THOMPSON, J. F. Pre-cooling and Storage Facilities. In: USDA. Agriculture Handbook Number 66 - DRAFT. United States: Department of Agriculture. (Revisado em 2004).

VIGNEAULT, C. et al. Plastic container opening area for optimum hydrocooling. Canadian Biosystems Engineering, v. 46, p. 3.41-3.44, 2004a.

VIGNEAULT, C.; de CASTRO, L. R.; GAUTRON, G. Effect of open handles on packages during precooling process of horticultural produce. ASAE Annual International Meeting, p. 6901-6908, 2004b.

W ELT I-CHANES, J.; VERGARA-BALDERAS, F.; BERMUDEZAGUIRRE, D. Transport phenomena in food engineering: Basic concepts and advances. Journal of Food Engineering, v. 67, n. 1-2, p. 113-128, Março 2005. 